\title{
The Use of Levelised Cost in Comparing Supply and Demand Side Options
}

\author{
Fane S., J. Robinson, S. White \\ Institute for Sustainable Futures, University of Technology, Sydney, \\ PO box 123, Broadway, NSW 2007 Australia (E-mail: Simon.Fane@uts.edu.au)
}

\begin{abstract}
This paper explores the use of levelised cost in planning for infrastructure networks. Levelised cost provides a useful measure comparing supply or conservation options on varying scales on an equivalent basis. Comparison is made to annualised cost, a metric often used as a means of comparing different supply side options. Urban water supply is used as the primary example, however levelised cost is equally applicable to other infrastructure networks, such as electricity or gas. The levelised cost is calculated as the ratio of the present value of projected capital and operating cost of an option to the present value of the projected annual demand supplied or saved by the option. The paper demonstrates that levelised cost is the constant unit cost of supply, provided by an option at present value. It is also the average incremental cost of the option at the point of implementation.

When translated to a unit cost, annualised cost does not account for unutilised capacity in large scale schemes, systematically under representing actual costs. By using levelised cost this inherent bias is removed. Use of levelised cost would facilitate the inclusion of smaller scale and more incremental supply options into infrastructure networks providing both economic and environmental benefits.
\end{abstract}

\section{Keywords}

Demand management, marginal cost, water conservation,

\section{INTRODUCTION}

Much has been written on how the water industry should apply integrated water resources management as a means of moving towards sustainability. This paper maintains that a simple step in this direction is the use of levelised cost (as defined in equation 1) as the metric of unit cost of supply. Unit cost of supply is a basic measure of cost effectiveness and how it is calculated will influence which options are seen as being economically appropriate. Howe and White, (1999) defined levelised cost, for water conservation options as "the present value of the cost of the option to the community divided by the present value of annual reduction in demand for water resulting from that option". The definition may be broadened to include both demand supplied and demand reduced or conserved, see equation 1 . In this equation $L C$ is the levelised cost (express in $\$ / \mathrm{kL}$ ), $P V($ costs) is the present value of all costs to the water service provider and consumer over the life cycle of the option at an accepted discount rate, and $P V$ (water demand conserved or supplied) is the present value of the projected annual water demands satisfied by a source or conserved by a water efficiency option or demand management program over the same period and using the same discount rate. It is argued that by using levelised cost the true value of conservation and smaller scale incremental supply options would be more apparent to utilities and the water industry in general.

$$
L C=\frac{P V(\text { costs })}{P V(\text { waterdemandconservedorsupplied })}=\frac{\sum C_{t} /(1+r)^{t}}{\sum W_{t} /(1+r)^{t}}
$$


Where $C_{t}$ is the cost (capital and operating) of the option in the year $t, W_{t}$ is the water demand conserved or supplied or in year $t$ and $r$ is the discount rate. The sum is taken over the same length of time in each case

Integrated resource management involves taking a step back from issues surrounding resource management and utilisation and looking for alternative solutions. One means of doing so for urban infrastructure networks such as water is to focus on the services provided instead of on bulk supply. Bulk supply is then seen as only one of a number of means of providing for the demand for services together with tapping distributed source of supply and conserving current supplies. For example, conservation is possible through increasing the end use efficiency of fittings and appliances. In the case of urban water, examples of demand management programs aimed at increasing end use efficiency include; the retrofitting of shower heads and toilets in existing dwellings, regulating the efficient of fittings installed in new developments, and offering water audits to commercial customers of a utility. Examples of distributed supply include rainwater tanks and localised greywater diversion for reuse at the household level.

Integrated resource management by the electricity industry in the US in the 80 's led to the development of the methodology for Least Cost Planning (LCP) (Beecher, 1995) The aim was to compare energy demand management programs with increased generation as sources of supply (Mieir et al. 1983). The basis of LCP is that conserved supplies and new supply are treated as equivalent. The methodology of least cost planning has since been applied to other urban infrastructure networks including water (Beecher, 1995; Dziegielewski et al. 1993, RMI, 1990) and gas (Greenberg \& Harshbarger, 1993). In all applications, end-use modelling of how supplied resources (energy or water) are actually used by consumers is central to LCP. End use models provide a more rigorous understanding of demand, and the basis for demand projection, as well as allowing for both the development of demand management programs and estimation of conservation outcomes. The more rigorous understanding of demand that comes from end use analysis and modelling also allow better demand projection for planning and evaluation of bulk supply augmentation.

\section{Marginal cost of supply}

The unit cost of increasing supply from an existing infrastructure network such as an urban water supply, is described as the marginal cost. Marginal cost is the cost incurred due to the production of one extra unit of supply. For urban water supply, the marginal cost may be viewed as a measure of the effect of incremental use on the network (Hanke, 1981) or the cost of an additional unit of consumption (Mann, et al, 1980). This unit cost include the operating cost for the extra unit produced and a fraction of the future capacity augmentation costs for the system as a whole. This factor is known as the marginal capacity cost and a number of methodologies have been suggested for approximating it (Mann, et al, 1980). Exactly how the capital cost of future augmentation are accounted for in varies between methodologies. By which ever methodology, marginal cost is seen to increase as increasing demand uses up existing capacity and need for augmentation approaches. Water pricing reform has driven attempts to estimate the marginal cost of supplies, with economic efficiency theoretically maximised when the price of water from a network is set at the marginal cost (Mann and Clarke, 1993.; Warford 1994 ; Herrington 1987)

Turvey (1969) described a method for calculating marginal capacity cost, where the cost numerator measured the change in present value due to moving the next planned capacity augmentation forward by a single year. The method uses a denominator that measures the volumetric increase in current demand that would require the planned capacity augmentation to be moved forward by a year (Mann and Clarke, 1993). The denominator in Turvey's method is unambiguously change in water demanded or water consumed measured in kilolitres. 
A number of authors, have described calculating the marginal cost for water supply using the term average incremental cost (AIC). Average incremental cost is defined as the discounted value of all incremental costs which will be incurred in the future to provide estimated additional demand divided by the discounted value of incremental output (Mann, et al, 1980 ; Herrington 1987 ; Warford 1994, ADB 1999, UKWIR, 1996). In other words, the AIC for a infrastructure network is the present value of the stream of capital and operating costs for projected supply requirements divided by the present value of the stream of projected outputs. Some confusion however exists over the denominator in this formula. Some authors give this as the total water supplied over a given period (such as 30 years) not discounted (Sutherland and Fenn ; 2000). Mann et al, (1980) do state that theoretically a different discount rate can be use for discounting the present value of output in AIC. The discount rate for the numerator of AIC should be set at the opportunity cost of capital while the denominator should be discounted at a rate equal to the time preference for consumption. Further conjecture exists, as to what the output stream in AIC represents and whether after an augmentation this should equal the design capacity or some fraction of the design capacity in order to account for unused capacity (Mann and Clarke, 1993). Other authors have uses the terms 'water delivered' (Herrington 1987 ; UKWIR, 1996) and 'production stream' of water (Warford 1994) to describe the output stream in an AIC function.

This paper asserts that the denominator for AIC is the same as that in the Turvey method, which is water demanded or consumed. Output in AIC is therefore the projected stream of increase in water demand that will be supplied over time. Conjecture around the output stream of AIC can then be understood. Mann and Clarke, (1993), Warford (1994) and Herrington (1987) all proposed calculating AIC in order to inform the price of water. However under a marginal cost-pricing scenario with marginal cost estimated using AIC, calculating the AIC becomes complicated. Average incremental cost is dependant on future demand, future demand is affected by the future price and future prices are determined by the future AIC.

Levelised cost as defined in this paper is a simplified version of the AIC term. The simplifying assumptions are that demand projections are independent of marginal cost and that the opportunity cost of capital is equal to the time preference for consumption. Under these assumptions, the levelised cost of an option is the AIC for that option at the point of its implementation. When conservation or distributed supply options are being considered within an infrastructure network, it is possible to directly compared the levelised cost of the new option to the current AIC of the network in order to determine an options cost effectiveness. This holds true as long as the network AIC is calculated under these same simplifying assumptions used in calculated the levelised cost.

\section{Annualised cost}

The calculation of an annualised capital cost $\left(A_{C C}\right)$ and it's combination with yearly operating cost and yield to give an annualised unit cost $(A C)$ of supply (expressed, for example, in $\$ / k L$ ) is currently an accepted metric for comparing new supply options within infrastructure networks of various types, (see equations 2 and 3). Annualised unit cost has also been used for valuing both water and energy conservation (RMI, 1990 ; Meier 1983, ; Wuppertal, 1996). Annualising capital is a means of spreading the initial cost of an option across the life time of that option while accounting for the time value of money. The cost of capital is 'annualised' as if it were being paid off as a loan at a particular interest or discount rate over the life time of the option. The result is a future value cost or constant annual cost of capital. The time period chosen ought to be (although often is not) the useful life of the scheme or option. This capital cost is then added to estimates of annual operating and maintenance cost $(O p)$ that are assumed to be constant and then divided by the estimated safe annual yield $(Y)$ from the scheme. The requirement for costs to be broken down into a single capital and constant operating fraction poses a problem for costing some options and demand management projects in particular. The Rocky Mountain Institute (RMI, 1990) overcame this limitation by 
taking the present value of all project costs and treating this figure as the capital cost $(C)$ in equation 2. The RMI approach still however requires a constant estimate of annual yield.

$$
A_{C C}=C \times \frac{r}{1-(1+r)^{-n}}
$$

Where $C$ is the initial capital cost, $r$ is the discount rate and $n$ is the life time of the option.

$$
A C=\frac{A_{C C}+O p}{Y}
$$

Comparing annualised unit to levelised cost, the key difference between the metrics is that the denominator for annualised unit cost is safe yield a solely volumetric term while the denominator of levelised cost is a function of future demand supplied or conserved, which is an economic term.

\section{LEVELISED COST AND DISCOUNTED WATER}

The term levelised cost has been use by authors to describe various methods for obtaining a unit cost of conserved water expressed on an equal, per unit basis, taking into account an appropriate discount rate (RMI 1990 ; Dziegielewski et al 1993 ; WDMF ,1996; Howe and White, 1999 ; Skeel, 2001). The Rocky Mountain Institute (RMI 1990) use the term to describe their adaptation of annualised unit cost for evaluating water efficiency programs. The Water Demand Management Forum in New South Wales (1996) and Dziegielewski et al (1993) independently defined levelised cost as present value costs divided by the total volume of water saved via a demand management program over a given period. Skeel,(2001) gives levelised cost as equivelent to AIC with water saved by a option as the output stream for the denominator. Similarly, both UKWIR (1996) and ADB (1999) use AIC in estimating the unit cost of conservation programs.

The conceptually problematic part of the levelised cost and average incremental cost formulae involves taking the present value of a stream of projected water supply. This aspect of the calculation which appears unreasonable at first glance can be explained from two perspectives. Firstly by correctly identifying the denominator of levelised cost as a function of future demand rather than as a volumetric quantity, as was the case in Howe and White (1999), discounting is understandable. The stream of satisfied demand provided by a option, despite being measured in kiloliters is a metric of the provision of utility, in the economic sense. It is therefore reasonable to discount this quantity over time in order to account for consumers time preference for consumption.

A second approach is to derive levelised cost as the constant cost of conserved or supplied demand from an option equivalent to the actual cost stream at present value. Another way of viewing this concept is that, the levelised cost is equal to the 'income' per unit that would need to be received from each unit of supply, for the project to 'break even' in present value terms. Similar arguments based on both constant cost and constant price have been presented by Stoft (1995) in justification for the discounting of energy conserved over time

\section{Constant cost of supply}

The levelised cost $(L C)$ for any option can be defined as that value of a unit cost constant over time that, if charged for the annual volume of water saved or supplied, would yield the present value of the cost of the option.

To demonstrate this, note that the present value cost for an option is given by the expression : 


$$
P V(\cos t)=\sum C_{t} /(1+r)^{t}
$$

Where $C_{t}$ is the cost (capital and operating) of the option in the year $t$, and $r$ is the discount rate to be applied. Therefore if levelised cost is the value of a constant unit cost of water over time then :

$$
P V(\cos t)=\sum L C^{*} W_{t} /(1+r)^{t}
$$

Where $W_{t}$ is the water supplied or conserved in year $t$.

Expanded this equation provides :

$$
P V(\text { costs })=L C^{*} \text { Wyear }_{1} /(1+r)^{1}+L C^{*} W_{\text {year }} /(1+r)^{2 \ldots \ldots \ldots \ldots . . .} L C^{*} W_{y e a r_{x}} /(1+r)^{x}
$$

Where Wyear, Wyear ${ }_{2}$ Wyear $_{x}$ is the water supplied or conserved in year 1 , year 2 and $x$ respectively.

This can then be easily rearranged to give: $P V($ costs) $=L C * P V$ (water supplied or conserved) an equivalent expression to the formula for levelised cost given in equation 1.

\section{COMPARING OPTIONS ON LEVELISED AND ANNUALISED UNIT COST}

A hypothetical scenario is proposed to illustrate the differences between using levelised and annualised unit cost for comparison of supply options. In a water supply network, demand is assumed to be rising at a rate of $2 \mathrm{GL}$ per annum due to population growth. Four supply augmentation options are considered; a $450 \mathrm{GL}$ capacity dam with a reliable yield of $350 \mathrm{ML} /$ day, a smaller $100 \mathrm{GL}$ off-stream storage reservoir with a safe yield of $75 \mathrm{ML} /$ day, a potable reuse plant using microfiltration and reverse osmosis capable of producing 16.5 $\mathrm{ML}$ /day from secondary treated effluent and household rain tanks backed up by the existing scheme supply. It is assumed that a rain tank with a volume of $15 \mathrm{kl}$ can be shown to provide an average $175 \mathrm{kl}$ per year to an average household in the region. The capital and operating costs and life span of each option are shown in table 1. Capital spending on both dam options would be spread evenly over a 5 year lead time. It is assumed that rain tanks or the membrane plant can be operational immediately. Operating cost is assumed to include network distribution costs for the centralised supply options. A discount rate of $9 \%$ is used.

Table 1 Operating and Capital Costs of Supply Options

\begin{tabular}{|l|c|c|c|c|}
\hline & $\begin{array}{c}16.5 \mathrm{ML} / \text { day potable } \\
\text { reuse plant }\end{array}$ & $\mathbf{4 5 0 \mathrm { GL } \text { dam }}$ & $\begin{array}{c}100 \mathrm{GL} \\
\text { reservoir }\end{array}$ & $\begin{array}{c}\text { Household rainwater } \\
\text { tank }\end{array}$ \\
\hline $\begin{array}{l}\text { Operating } \\
\text { cost }\end{array}$ & $\$ 400 / \mathrm{ML}$ & $\$ 100 / \mathrm{ML}$ & $\$ 200 / \mathrm{ML}$ & $\$ 50 /$ year \\
\hline Capital cost & $\$ 50 \mathrm{M}$ & $\$ 275 \mathrm{M}$ & $\$ 150 \mathrm{M}$ & $\$ 1500$ \\
\hline Life time & 20 years & 100 years & 100 years & 50 years \\
\hline
\end{tabular}

Table 2 Levelised and Annualised Costs of Supply Options Discounted at $9 \%$

\begin{tabular}{|l|c|c|c|c|}
\hline & $\begin{array}{c}16.5 \text { ML/day potable } \\
\text { reuse plant }\end{array}$ & $\begin{array}{c}\mathbf{4 5 0 G L} \\
\text { dam }\end{array}$ & $\begin{array}{c}100 \mathrm{GL} \\
\text { reservoir }\end{array}$ & $\begin{array}{c}\text { Household rainwater } \\
\text { tank }\end{array}$ \\
\hline Levelised cost & $\$ 1.29 / \mathrm{kl}$ & $\$ 1.32 / \mathrm{kl}$ & $\$ 1.16 / \mathrm{kl}$ & $\$ 1.00 / \mathrm{kl}$ \\
\hline Annualised unit cost & $\$ 1.31 / \mathrm{kl}$ & $\$ 0.30 / \mathrm{kl}$ & $\$ 0.69 / \mathrm{kl}$ & $\$ 1.07 / \mathrm{kl}$ \\
\hline
\end{tabular}

The results in table 2 show that significant differences are possible between levelised and annualised unit costs of supply for large scale projects. On annualised unit cost, the large dam appears the most economic option with a unit cost of supply of only $\$ 0.30 / \mathrm{kl}$. This cost however does not reflect the fact that with projected rate of demand increase, it would be nearly 70 years before the safe yield from this project was fully utilised. In levelised cost terms the large dam option is shown to be the least cost effective with a cost of supply of $\$ 1.32 / \mathrm{kl}$. 
The same effect can be seen to a lesser extent for the off-stream reservoir option. Based on levelised cost, in this example the installation of household rain tanks integrated into the potable supply is the most economic option for the supply network described. network described.

\section{Comparing water supply and conservation : Accounting for the true costs of supply}

When a distributed supply option such as household rain tanks is compared to centralised water supply, the costs of the distribution network need to be accounted for. The distribution cost can be included either in the cost of the centralised supply, as in the example above, or subtracted from the cost of the distributed supply as an avoided cost. By the same rationale, when considering water conservation, not only the distribution costs, but also any avoided wastewater treatment costs need to be accounted for.

In order to illustrate the application of levelised unit cost to conservation two further options are added to the hypothetical scenario described above. The first is a retrofit program aimed at existing households. This program would cost $\$ 40 \mathrm{M}$ over four years and reach approximately 200,000 households. The second is a development control plan for all new developments requiring AAA-rated fittings in new developments and regulating the lawn varieties to be planted and other outdoor water use regulations. It is assumed that the development control costs $\$ 0.5 \mathrm{M}$ per year to administer and ensure compliance. The projected conservation outcomes are shown in figure 1

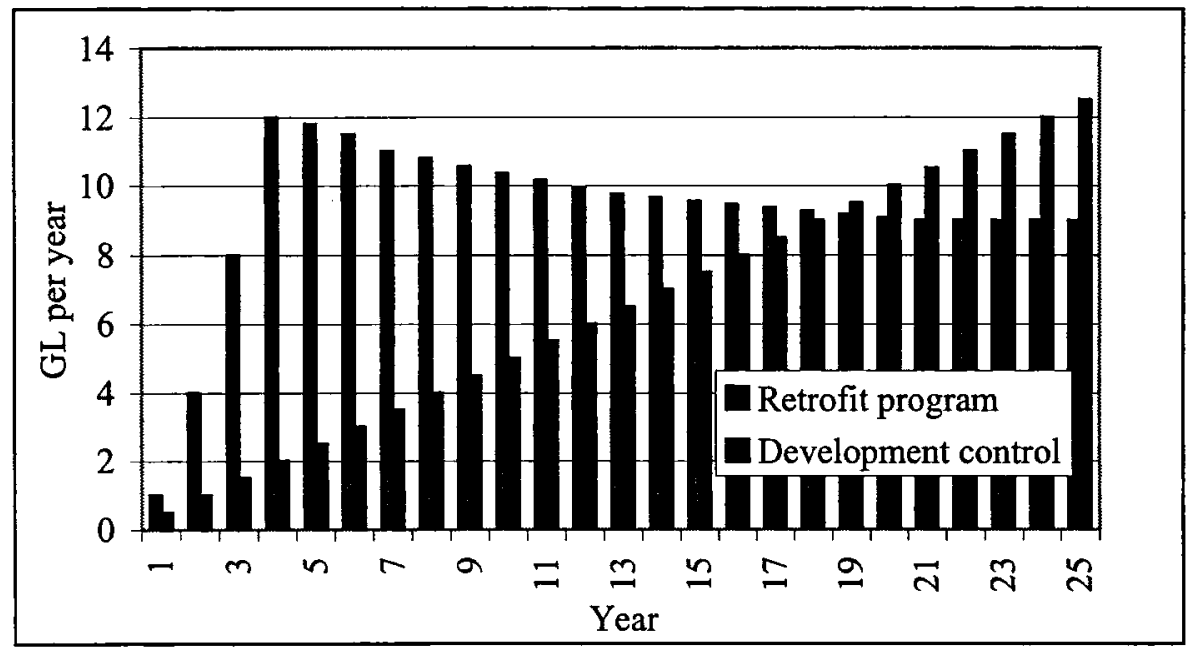

Figure 1 Supplies Conserved

Not including the avoided cost of wastewater, the levelised cost of the retrofit program and development control as described are $\$ 0.33 / \mathrm{kl}$ and $\$ 0.01 / \mathrm{kl}$ respectively. The retrofit program would have an amortised unit cost of $\$ 0.41 / \mathrm{kl}$, significantly higher than the corresponding (annualised) unit cost of the large dam option. Without a constant yield, no amortised unit cost is possible from the development control option. A value for avoided wastewater (assumed to average $\$ 0.03 / \mathrm{kl}$ conserved) must be subtracted before comparison is made to supply. The resulting levelised costs show a net benefit from each kilolitre saved by the development control option. These 'net' levelised costs are given in table 3 together with the cost of a demand management program combining both conservation options.

Table 3. 'Net' levelised cost of conservation options discounted at $9 \%$

\begin{tabular}{|l|c|c|c|}
\hline & Retrofit program & Development Control & Combined program \\
\hline Levelised cost & $\$ 0.30 / \mathrm{kl}$ & $-\$ 0.02 / \mathrm{kl}$ & $\$ 0.21 / \mathrm{kl}$ \\
\hline
\end{tabular}




\section{DISCUSSION}

Levelised cost as defined in this paper is a derivative of the average incremental cost term used to calculating the marginal cost for a supply network. The levelised cost of an option being the AIC for that option at the point of it's implementation, under a number of conditions. These condition are that, the output stream used in the denominator of the AIC term is projected demand supplied or conserved by the option, that demand projections is independent of marginal cost and that the same discount rate is used for both the cost and output streams.

Discounting the water output stream in the calculation of both levelised cost and average incremental cost has been shown to be valid and appropriate to account for the time preference of consumption. Authors that have described AIC and levelised cost formulations where the denominator is not discounted (Sutherland and Fenn , 2000 ; Dziegielewski et al , 1993 ; WDMF , 1996) therefore make an implicit assumption of no time preference for consumption. Such an assumption is problematic for comparing options on different scale or with different life times. If a long assessment period is taken, such as the life of a dam, then not discounting output will give an unrealistically low unit cost of supply. However if a shorter assessment period is used, as prescribed in Sutherland and Fenn (2000) or WDMF (1996), then the bias will favour smaller scale options.

A comparison of levelised and annualised unit cost has shown that choice of metric for unit cost of supply can strongly influence which options are seen as economic. Annualised unit cost is also seen to have an inherent bias in favour of large scale schemes because periods when safe yield will be in excess to requirements are not considered in the calculation. Unlike annualised cost, levelised cost allows a fair comparison of supply and conservation options across the range of scales because both denominator and numerator are discounted to present value. 'Lumpiness' in either annual costs or annual volume of water supplied or both pose no problem in calculation of unit cost. With annualised unit cost only 'lumpiness' in costs can be accounted for.

Calculating a levelised requires considerably more information about future demand and supply than an annualised unit cost with only a single estimate of yield is required for calculating annualised unit cost. Levelised cost requires estimates of the stream of annual demands satisfied or conserved by an option. Such information on demand and supply projections is generated in the process of least cost planning making leveised cost easily used in this field. Despite the increased requirements for calculating levelised costs, the simplicity of annualised unit costing is however mis leading and should be avoided. The use of annualised unit cost as a measure will work well only for comparison of small scale options where yield is constant and fully utilised from the date of project implementation.

Using levelised cost it is possible to evaluate the merits of large projects in comparison to a series of smaller ones. In particular a series of water conservation and distributed supply options could be considered and compared as an alternative to increasing bulk supplies. Such an incremental approach to supply also has a lower risk in relation to changing projections of demand.

\section{CONCLUSIONS}

The use of annualised unit cost for large scale supply schemes is inherently mis leading. The unit cost calculated by this method does not represent the true cost of supply. Excluded are periods when demand can be expected to be significantly less than safe yield. The result is a systematic under representation of the cost of supply from large scale supply projects such as new dams. 
The use of levelised cost, based on projected demand supplied or conserved as describe, for infrastructure network planning in water, gas and electricity would allow the comparison of supply and conservation options on varying scales on an equivalent basis. This should facilitate the inclusion of smaller scale, incremental options for meeting demand into infrastructure networks and promote least cost service provision. Further, the use of levelised cost as the metric for deciding cost effectiveness should have resource conservation and environmental benefits as demand management programs and efficiency options are often of this smaller scale and incremental type.

\title{
REFERENCES
}

Asian Development Bank, (1999) Least-cost analysis, chapter 4, Hand book for economic analysis of water supply, ADB publishing

Beecher, J (1995) Integrated Resource Planning Fundamentals. Journal AWWA. 87 (6): 34-48 Dziegielewski B., Opitz E., Kiefer J., and Baumann D. (1993). Evaluating Urban Water Conservation Programs: A Procedures Manual, AWWA Carbondale IL, USA.

Greenberg V. and Harshbarger S. (1993). Least cost selection of energy conservation measures for regulated gas utilities. Energy Economics.July 93

Howe C. and White S. (1999). Integrated Resource Planning for Water and Wastewater: Sydney Case Studies. Water International, 24 (4) : 356-362.

Hanke S, (1981) On the marginal cost of water supply, Water Eng. and Mgmt, 120(2) 60-63 Herrington P. (1987). Pricing of Water Services. OECD, Paris.

Mann P., Saunders R. and Warford J. (1980). A note on capital indivisibility and the definition of marginal cost. Water Resources Reseach 16 ( 3) : 602-604.

Mann P and Clarke D, (1993) Marginal-Cost Pricing: Its Role in Conservation, Journal AWWA

Mieir A.K., Wright J. and Rosenfeld A.H. (1983). Supplying Energy Through Greater Efficiency.

University of California Press, Berkeley, CA.

The Rocky Mountain institute, (1990) Water efficiency, report

Stoft, S. (1995) The economics of conserved energy "supply" curves, Energy Journal, 16 (4).

Skeel T, (2001) Water conservation potential assessment : a tool for strategic resource, management Efficient use and management of water for urban supply, Conference proceeding Madrid

Sutherland D. and Fenn C. (2000) Assessment of water supply options, thematic review prepared for the World Commission on Dams

Turvey, R. (1969) Marginal Cost Economics Journal 79(314) : 282-299.

UKWIR, (1996) Economics of demand management, URWIK/Environment agency

Warford J. (1994) Marginal Opportunity Cost Pricing for Municipal Water Supply, EEPSEA discussion paper, August 94

Water Demand Management Forum(1996) Water demand management: A framework for options assessment, Report to the Independent pricing and regulatory tribunal of NSW. Wuppertal Institute, (1996) Rational planning techniques (RPT) A tool to enhance energy efficiency? European parliament directorate general for research, working papers W-21

\author{
CONTACT \\ Fane S \\ Institute for Sustainable Futures \\ University of Technology, Sydney \\ PO box 123, Broadway \\ NSW 2007 Australia \\ (E-mail: Simon.Fane@uts.edu.au)
}

